\title{
Structural Changes Undergone During Thermal Aging and/or Processing of Unstabilized, Dry- blend and Rigid PVC, Investigated by FTIR-ATR and Curve Fitting
}

\author{
Zineb Hadj Amar, Salem Fouad Chabira, Mohamed Sebaa, Benchatti Ahmed* \\ Mechanics Laboratory (lme), University of Amar Telidji, Ghardaïa Road, B.P. 37G, 3000, Laghouat, Algeria
}

Corresponding Author Email: s.chabira@lagh-univ.dz

https://doi.org/10.18280/acsm.430109

Received: 26 October 2018

Accepted: 17 January 2019

\section{Keywords:}

PVC, aging, ATR-FTIR, curve fitting, mechanical properties

\begin{abstract}
Thermal aging below the glass transition temperature $(\mathrm{Tg})$, during three months, of Poly (vinyl chloride) (PVC) under its three different aspects, powder (p-PVC), dry-blend and Unplasticized (u-PVC) or rigid form was performed. The stabilizing system used is a commercial compound constituted by lead based stabilizers, internal and external lubricants. The ageing of PVC under these three different aspects was performed in a thermo-regulated oven at $60{ }^{\circ} \mathrm{C}$, temperature close of the ground temperature in Sub-Sahara region (Ghardaïa, Algeria). A sampling at regular interval allowed following the microstructural changes undergone by these materials. Such an approach revealed that the additives used in the PVC recipe not only assist processing but also ensured a good material stabilization when thermal aged. The results obtain can help producers to modify the PVC recipe to improve the heat resistance of the PVC tubes to make them more performing in the very hot and deleterious Saharan environment.
\end{abstract}

\section{INTRODUCTION}

Water transportation in sub-Sahara region is of prime importance in terms of water saving and rainfall deficit. PVC tubes convey fresh water to agricultural surfaces to ensure their irrigation; they are also used for wastewater evacuation. $\mathrm{PVC}$ is one of the most widely used thermoplastics material, because of its good mechanical properties, chemical resistance, ease of processing and low cost [1-6].

However, it cannot be transformed as tube without a stabilization system since the heat needed during its implementation combined to the shearing effects of the extrusion-screw lead to an irremediable degradation of this material inside the processing tool $[7,8]$.

It has been demonstrated that the stabilization system is not entirely consumed during processing. The unreacted concentration can also prevent the material degradation in its environment of use. In fact, during the last decades, the ability of stabilized PVC to withstand aggressive environments has been the subject of many studies [1,9-12].

A case study is the use of this product in a sub-Sahara region (at Ghardaïa, 32 $29^{\prime} 00^{\prime \prime}$ Nord, 341'00" Est., Algeria) where during summer (i.e. June, July and August) the daily insolation can last 13 hours, and the ground surface storing solar energy can reach temperature exceeding $50{ }^{\circ} \mathrm{C}$ and even $57^{\circ} \mathrm{C}$ at 20 $\mathrm{cm}$ depth. Even during the night, the stored energy is released and the ground temperature remains high. Moreover, according to the Stefan-Boltzmann law, the black color of the tube acts as a blackbody absorbing the incident solar energy during the day [13]. Therefore, the exposed surface of the tube can reach temperature around $60^{\circ} \mathrm{C}$. During summer buried or on ground the plastic tubes are subjected to heat stresses leading to degradation.

PVC tube and pipes used to convey hot water in some factories in Ghardaïa (plastic-plants, gypsum-plant, etc.), show crazes on their surfaces, and for longer time of use, cracks occur leading to water leak and requiring thus their replacement. Therefore, the understanding of the impact of heat on the service life-time of those PVC tubes becomes important for the assessment of the periodicity of their replacement and their impact on the environment. The understanding of the degradation mechanisms and/or stabilization of this material can contribute to prevent an early degradation by avoiding exposure to deleterious environmental factors. In this way one can contribute to decrease the amount of rejected plastic only by rational use.

Therefore the study of this material's degradation under its different aspects i.e. pure PVC powder, powder mixed with stabilizers and fillers and finally the processed mixture gives a good insight of how the different components of the PVC tube behave individually to the thermal aging. Finally, it allows understanding how stabilizers assist processing, but also how they prevent PVC aging during heat stress.

\section{EXPERIMENTAL}

\subsection{Material and processing}

The pristine PVC powder used in this study is (Oxyvinyls225P; PVC-S; OxyVinyls, LP-Dallas, Texas). The stabilized grade (Dry-blend) is a mixture of PVC powder with filler, lubricants and lead based heat stabilizers. The concentration in weight of the different constituents in the recipe was as follows:

$86 \%$ PVC powder; $2 \%$ of the as received stabilizer system (tribasic lead sulfate/lubricant; Chemson-Polymer Additive AG, Austria); $5 \%$ Calcium carbonate filler (OMYALITE-95T, Omya-SAS, Paris, France); 7 \% Carbon black.

Processing. The above products in their respective proportion were blended in a plastification high speed mixer (plas-mec, SN: 2998; Pozzolo-Varese, Italy) during 10 minutes at $\left(\mathrm{T} \leq 120^{\circ} \mathrm{C}\right)$ and a rotation speed around $1500 \mathrm{rpm}$. 
This step was carried out to ensure a good distribution of the additives between macromolecular grains of PVC.

The dry-blend obtained was poured in another mixer and gradually cooled till $40{ }^{\circ} \mathrm{C}$. Then, the whole was processed as tubes in a twin-screw extruder (Cincinnati, Germany) at $175^{\circ} \mathrm{C}$ (see Figure 1). These unplasticized PVC (u-PVC) tubes for water transportation are manufactured by (PLASTUBsociety, Ghardaïa, Algeria) according to the ISO: EN-1452-2 standard.

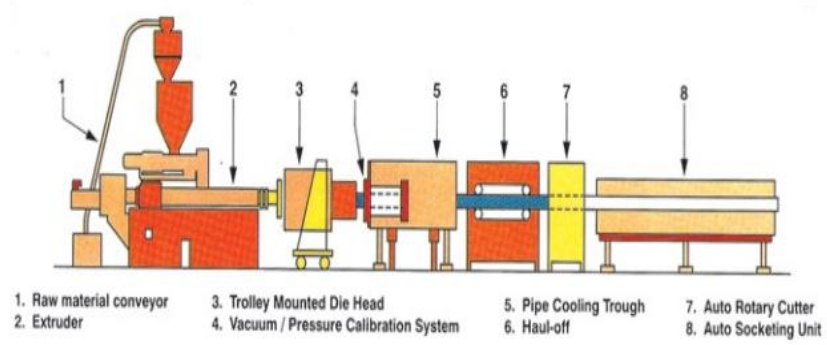

Figure 1. Typical scheme of (u-PVC) tube extrusion system

Table 1 collects some physical and thermal properties of pristine PVC before processing and those of the stabilized PVC transformed into rigid tube. These properties are provided first by the raw material supplier (oxyvinyls, LP) via a certificate of analysis of the pristine PVC and secondly by the transformer (PLASTUB-SARL) providing a datasheet of the PVC tube. It can be still mentioned that the glass transition temperatures of the two PVC types were determined by DSC analysis, performed by some of us in laboratory.

Table 1. Some physical and thermal properties of pristine $\mathrm{PVC}$ and stabilized rigid PVC

\begin{tabular}{|c|c|c|c|}
\hline Property & $\begin{array}{l}\text { Pristine } \\
\text { PVC }\end{array}$ & $\begin{array}{l}\text { Rigid } \\
\text { PVC }\end{array}$ & $\begin{array}{c}\text { Test } \\
\text { Method }^{1}\end{array}$ \\
\hline $\begin{array}{c}\text { Apparent bulk density } \\
{\left[\mathrm{kg} / \mathrm{m}^{3}\right]}\end{array}$ & 535 & $\begin{array}{l}1390- \\
1450\end{array}$ & ISO 1183 \\
\hline $\begin{array}{l}\text { Inherent viscosity } \\
{\left[\mathrm{m}^{3} / \mathrm{kg}\right]}\end{array}$ & 0,09 & 0,114 & ISO $1628-2$ \\
\hline $\mathrm{K}$-value & 65 & 67 & DIN 53726 \\
\hline $\begin{array}{l}\text { Glass transition } \\
\text { temperature }{ }^{2}\left[{ }^{\circ} \mathrm{C}\right]\end{array}$ & 79,25 & 79,41 & I \\
\hline $\begin{array}{l}\text { Specific heat } \\
{\left[\mathrm{kJ} /\left(\mathrm{kg} .{ }^{\circ} \mathrm{C}\right)\right]}\end{array}$ & l & 0,10042 & / \\
\hline $\begin{array}{l}\text { Softening temperature } \\
\text { (Vicat } 5 \mathrm{~kg})\left[{ }^{\circ} \mathrm{C}\right]\end{array}$ & I & $\geq 80$ & BS EN 727 \\
\hline $\begin{array}{c}\text { Thermal conductivity } \\
{[\mathrm{W} /(\mathrm{m} . \mathrm{K})]}\end{array}$ & / & 0,13 & DIN 52612 \\
\hline $\begin{array}{l}\text { Coefficient of thermal } \\
\text { expansion }\left[{ }^{\circ} \mathrm{C}^{-1}\right]\end{array}$ & I & $7 \times 10^{-5}$ & DIN 53752 \\
\hline
\end{tabular}

\subsection{Thermal aging}

Thermal aging was performed on the PVC under its three different aspects, pristine PVC powder (p-PVC), Dry-blend and $\mathrm{u}-\mathrm{PVC}$.

To perform thermal aging, the two unprocessed products (i.e. Dry-blend, p-PVC) were poured in glass petri dishes before being introduced in the oven, while the rigid aspect test pieces were cut from the tube by means of a programmed mill cutter.
The oven temperature (Memmert, F.Nr207.0509E) was fixed at $60{ }^{\circ} \mathrm{C}$ and aging took place during 90 days. A regular sampling of each type of the products was performed every 30 days.

\subsection{Characterization techniques}

(1) Fourier transforms infrared (FTIR) spectroscopy

A Spectrum Two FTIR spectrometer, equipped with the UATR-Two maintained by Perkin Elmer (USA), was used to perform the infrared analysis. The ATR-spectra were obtained by analyzing the samples surfaces in contact with a diamond crystal. The infrared spectra were collected in transmission mode over the wavenumber range from $4000-400 \mathrm{~cm}^{-1}$ at a 4 $\mathrm{cm}^{-1}$ optical resolution and using 32 scan repetitions. A separate background spectrum was subtracted in each collection. The specific absorption peaks were analyzed from the FTIR spectra delivered by the equipment. For each peak the optical density (OD) was determined following the usual definition as in Eq. (1) [15].

$O D=\ln \left(\frac{I_{0}}{I}\right)$

where, $\mathrm{I}_{0}$ : the reference infrared intensity corresponding to the baseline of the spectrum at the peak wavenumber. I: the minimum intensity at the base of the peak.

Mathematical curve-fitting. In order to identify the species constituting the complex absorption bands in the different regions of the FTIR spectrum, a mathematical curve-fitting was performed to identify the initial existing products and those evolving during aging. The curve-fitting was performed using the second derivative method in the Origin.Pro software package (version 9.0). The quality of the fit is controlled using the determination coefficient, which was $\mathrm{R}^{2}>0.998$ for the absorption band of each sample. The residual sum of the squares was determined to be Chi-square $<10^{-5}[16]$.

\section{(2) Mechanical testing}

Tensile tests on u-PVC were run with a (Rochdale machine 500-50AT, England), accordingly to the ISO 6259-2 standard with dumbbell shaped test pieces cut out of the original PVC tubes. The aspect and the dimensions of the test pieces are indicated in (Figure 2).

All the tests were conducted at $\left(\mathrm{T}=23^{\circ} \mathrm{C} \pm 2{ }^{\circ} \mathrm{C}\right)$ and at a relative humidity $(\mathrm{RH} \approx 30 \% \pm 5 \%$ ). The results of the tensile test are presented in terms of the nominal stress Eq. (2) and nominal strain Eq. (3). The elastic modulus was determined as the initial slope of the $\sigma(\varepsilon)$ curve.

$\sigma=\frac{F}{\left(W_{0} \times T_{0}\right)}$

where, $\mathrm{W}_{0}$ : Width of the narrow section. $\mathrm{T}_{0}$ : Thickness sample.

$\varepsilon=\left(\frac{L}{L_{0}}\right)-1$

where, $\mathrm{L}_{0}$ : initial distance between grips. L: current distance between grips.

To optimize the duration of the tests, the strain rate was fixed at a low value to the yield point $\left(\mathrm{d} \varepsilon / \mathrm{dt}=1 \times 10^{-3} \mathrm{~s}^{-1}\right)$ and 
the test was performed until fracture occurred. The stress and strain at break $\left(\sigma_{\mathrm{b}}, \varepsilon_{\mathrm{b}}\right)$ were measured while the sample reached its ultimate elongation before ductile or semi brittle failure occurred [15].

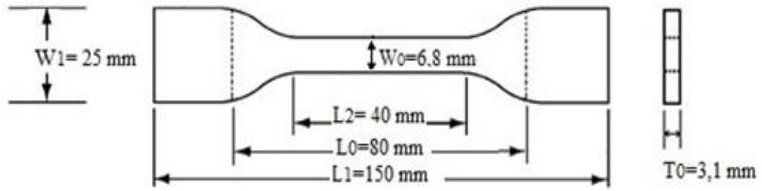

Figure 2. Tensile test piece of rigid PVC

\section{RESULTS AND DISCUSSION}

Characterization methods performed on the three different aspects of PVC allows seeing how thermal aging and the blending with a stabilizer system and fillers normally used to assist processing modifies the molecular structure of the $\mathrm{p}$ PVC. The third aspect is to highlight the effects of additives during the dry-blend processing. The resulting rigid tubes were also thermally aged and the effect of the unconsumed stabilizer was checked. Finally a comparison between the three different aspects of the product (p-PVC, dry-blend and u-PVC) toward the thermal aging has been done.

\subsection{Structural characterization of the pristine PVC powder, additives and dry-blend}

In order to disassociate the IR signals of the functional groups belonging respectively to the p-PVC, stabilizer system, filler and dry-blend their respective IR-spectra are reported in (Figure 3). Such a representation allows recognizing the signal of each product.

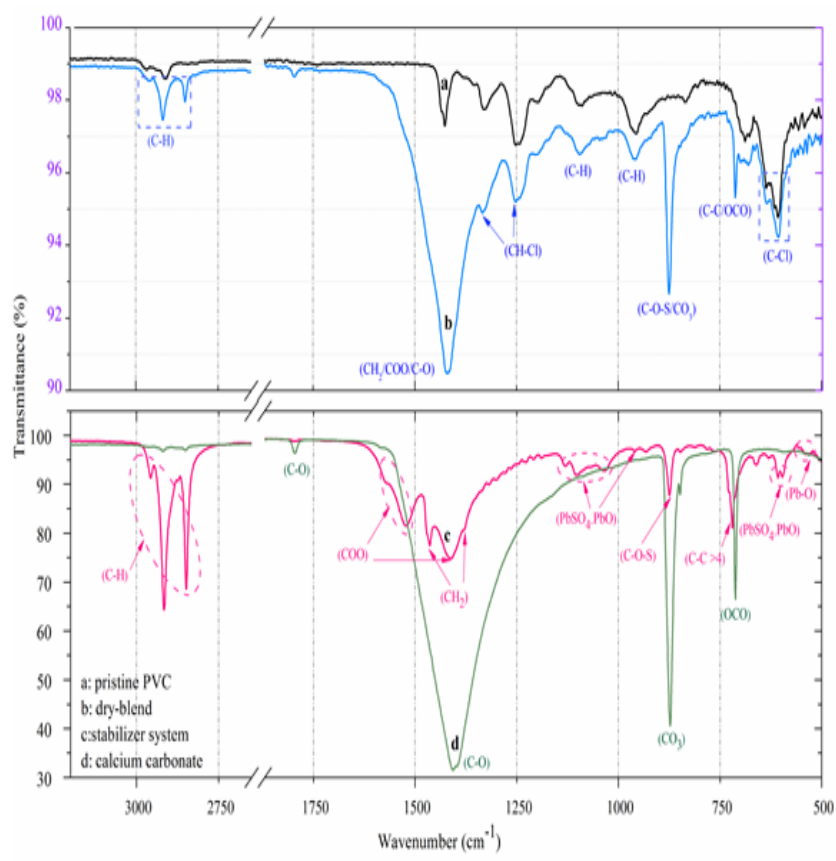

Figure 3. FTIR-ATR spectra of pristine PVC, stabilizer system, calcium carbonate filler and dry-blend
Pristine PVC. The few absorption bands visible at 610, 635 and $690 \mathrm{~cm}^{-1}$ of the p-PVC in the spectrum (a) correspond to the different stretching vibration modes of the $(\mathrm{C}-\mathrm{Cl})$ bond. Those at 1088 and $1095 \mathrm{~cm}^{-1}$ belong to the stretching vibration of the $\left(v\right.$ C-C) bond. The vibration at $1197 \mathrm{~cm}^{-1}$ corresponds to the out-of-plane bending vibration $\left(\delta_{\text {out-of-plane }}\right)$ of the $(\mathrm{C}-\mathrm{H})$ bond. While, those at 1253 and $1329 \mathrm{~cm}^{-1}$ correspond respectively to the $\left(\delta_{\text {in-plane }}\right.$ and $\left.\delta_{\text {out-of-plane }}\right)$ of the $(\mathrm{C}-\mathrm{H})$ bond in the $(\mathrm{CH}-\mathrm{Cl})$ group. The $\mathrm{CH}_{2}$ group vibrations appear at 955 and at $1425 \mathrm{~cm}^{-1}$. The other vibrations appearing between 2850 and $3010 \mathrm{~cm}^{-1}$ belong to the different vibration modes of the $\mathrm{CH}$ and $\mathrm{CH}_{2}$ bonds [17-19].

Stabilizer system. The as-received stabilizer system is a complex trade composition of several products (such as tribasic lead sulfate and lubricant). However, a rigorous FTIR analysis of this system has revealed the existence of other additives. In the spectrum (c) it appears that in addition to the tribasic lead sulfate (TBLS), lead stearate $\left(\mathrm{PbSt}_{2}\right)$ also exists. This thermal stabilizer provides a synergistic effect to the system. Calcium stearate $\left(\mathrm{CaSt}_{2}\right)$ and wax paraffin are also identified and are known to ensure internal and external lubrication respectively.

The different vibrations of the carboxylate $\left(\mathrm{COO}^{-}\right)$in the stearate component appear at 539 and $1523,1576 \mathrm{~cm}^{-1}$ shows respectively the bending vibration, the symmetric $\left(v_{\mathrm{s}}\right)$ and antisymmetric stretching $\left(v_{\text {as }}\right)$ [20-22].

A series of weak peaks visible at $\left(1160-1350 \mathrm{~cm}^{-1}\right)$ are attributed to the ( $\left.\delta_{\text {in-plane }}, \delta_{\text {out-of-plane }}\right)$ of the methylene groups in the stearates $[20,21]$. The absorption bands at $(2850,2918$ and $\left.2874,2956 \mathrm{~cm}^{-1}\right)$ belong to $\left(v_{\mathrm{s}}\right)$ and $\left(v_{\mathrm{as}}\right)$ of the $(\mathrm{C}-\mathrm{H})$ bond. While those at 1380,1463 and $1471 \mathrm{~cm}^{-1}$ correspond to the $\left(\delta \mathrm{CH}_{2}, \delta \mathrm{CH}_{3}\right)$. The peaks at 720 and $729 \mathrm{~cm}^{-1}$ reveal that all the precedent structures belong to long chains hydrocarbon of four or more methylene units. These vibrations have been identified by others to belong to the long aliphatic chains existing either in wax or in the lead based stabilizer [20, 21, 23-27].

Most of the stearate based stabilizers contain a small amount of fatty acids as stearic acid (HSt). In fact, a weak absorption bands specific to the HSt are observable at 1720 , $932 \mathrm{~cm}^{-1}$ which corresponds to the $(v \mathrm{C}=\mathrm{O})$ and $\left(\delta_{\text {out-of-plane }} \mathrm{O}\right.$ H) respectively [27].

A stronger peak at $1413 \mathrm{~cm}^{-1}$ belonging to the $(\delta \mathrm{C}-\mathrm{H})$ bond of a methylene group bonded to carboxylic acid supports the previous assertion [27]. The remaining peaks at 1131, 1036, $1101,959 \mathrm{~cm}^{-1}$ and at $607,596 \mathrm{~cm}^{-1}$ correspond to the ( $v_{\text {as }}$ $\left.\mathrm{PbO} \mathrm{PbSO}_{4}\right)$, and $\left(v_{\mathrm{s}} \mathrm{PbO}_{\mathrm{PbSO}}\right)$ respectively in TBLS [28, 29]. The vibrations at $\left(847,874 \mathrm{~cm}^{-1}\right)$ are those of the bonds of the (S-O-C) structure, while that at $631 \mathrm{~cm}^{-1}$ belongs to the ( $\left.\delta_{\text {in-plane }} \mathrm{S}-\mathrm{O}\right)$ bond of the alkyd sulfate [30-32].

This allows supposing that TBLS has probably reacted with either $\mathrm{PbSt}_{2}, \mathrm{CaSt}_{2}$ or wax during the mixing in the manufactory, promoting thus the formation of covalent bonds between sulfates and carbon atoms of the other components of the stabilizer system.

The remaining vibrations appearing at 476,449 and $434 \mathrm{~cm}^{-}$ ${ }^{1}$ belong to the symmetric bending vibration of $(\mathrm{Pb}-\mathrm{O})$ in TBLS $[28,29,33]$, but they can also belong to the $\left(\delta \mathrm{COO}^{-}\right)$in the stearate [20].

Calcium carbonate. On the IR spectrum (d) of the calcium carbonate $\left(\mathrm{CaCO}_{3}\right)$ appears a large absorption band at 1405 $\mathrm{cm}^{-1}\left(v_{\mathrm{as}} \mathrm{C}-\mathrm{O}\right)$. A peak of weak intensity at $1795 \mathrm{~cm}^{-1}\left(v_{\mathrm{s}} \mathrm{C}-\mathrm{O}\right)$ 
and two other peaks at $875 \mathrm{~cm}^{-1}\left(\delta_{\text {out-of-plane }} \mathrm{CO}_{3}\right)$ and $712 \mathrm{~cm}^{-1}$ ( $\delta_{\text {in-plane }}$ OCO) [34-38].

Dry-blend. The dry-blend shows a particular IR spectrum (b) a combination between the spectrum of the p-PVC and the others additives. The peaks belonging to the stabilizer and the $\mathrm{CaCO}_{3}$ are less intensive in the dry-blend because of their lower concentration (4 wt \%) moreover a new peak appears. In fact, a composite absorption band centered at $1425 \mathrm{~cm}^{-1}$ is observed. It encompasses the vibrations of $\mathrm{CH}_{2}$ in the p-PVC, $(\mathrm{C}-\mathrm{H})$ in the stabilizer and $\mathrm{CO}_{3}{ }^{-}$in $\mathrm{CaCO}_{3}[17,21,34,35]$. In the following to highlight the effect of the stabilizer on PVC during processing a comparison between the dry-blend and u$\mathrm{PVC}$ has been done. Then, to see its effect during thermal aging a comparison between the p-PVC, dry blend and u-PVC was also performed.

\subsection{Effect of processing on the PVC structure when transformed into rigid tube}

In (Figure 4) are reported the IR-spectra of the dry-blend and that of u-PVC. After processing the material was slightly oxidized because of the thermo-mechanical shearing developed inside the extruder. The damages caused to the macromolecular chains are scissions, oxidation by reaction with environmental oxygen and replacement of labile chlorine by $\left(\mathrm{COO}^{-}\right)$provided by the stabilizer.

Therefore processing has modified the global aspect of the IR spectrum, the absorption bands belonging to the carboxylate (1500-1620 $\left.\mathrm{cm}^{-1}\right)$ became visible.

A new wide absorption band around $3400 \mathrm{~cm}^{-1}$ inexistent in the dry-blend develops in u-PVC and belongs to hydroperoxides. The characteristics peaks of the PVC and its additives $(610,875,965,1101,1198,1253,1329,1425,2853$ and $2918 \mathrm{~cm}^{-1}$ ) became also bigger and more intensive in $\mathrm{u}-$ PVC [18, 19, 21, 27].

The changing aspect of the IR spectrum revealed that processing enhanced the signal of the characteristic peaks of either the PVC or stabilizer due to chemical reactions. Moreover, the dry-blend offers fewer surfaces in contact with the crystal of the apparatus than u-PVC.

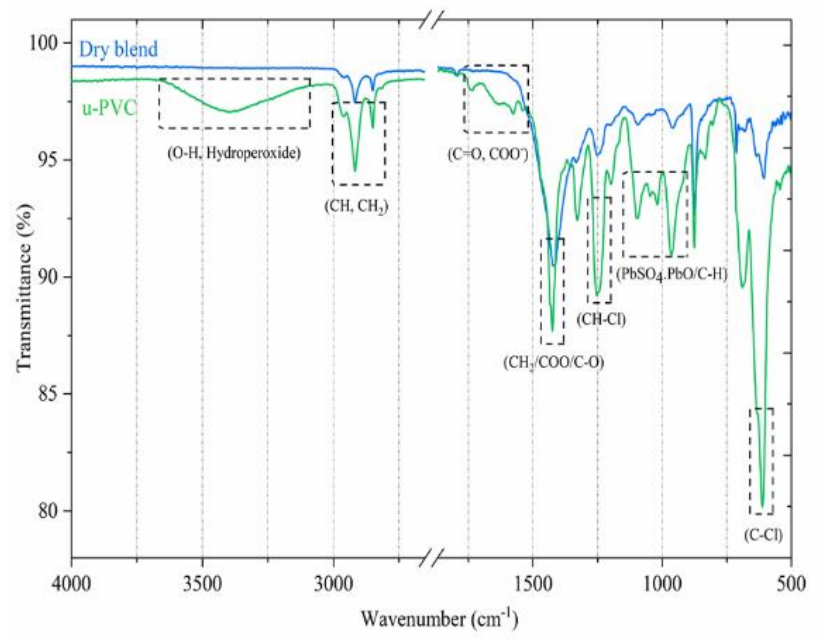

Figure 4. FTIR-ATR spectra of the dry-blend and u-PVC after processing

Curve-fitting to identify the stabilizer reactions during processing. The knowledge of the stabilization mechanism under heat stress degradation is very important to estimate the effectiveness of stabilizer system during processing. It has been reported that under the combined effect of the screwextrusion shearing and heat of the barrel into the processing tool, the stabilizer compound may replace labile chlorines, scavenges evolved hydrogen chloride $(\mathrm{HCl})$, blocks the growing polyenes and destroy peroxides and/or peroxyradicals [39].

The stabilization reactions were revealed by the changing aspect of the IR spectrum of u-PVC in the (1500-1800 $\left.\mathrm{cm}^{-1}\right)$ range. In fact this spectrum region encompasses all the vibrations of the carboxylates and carbonyls. To highlight all the oxidation products formed via the $\mathrm{PbSt}_{2}$ and $\mathrm{CaSt}_{2}$ reaction with PVC during processing or merely by polymer oxidation, a mathematical curve-fitting using the second derivative method applied to their absorption bands has been performed (Figure 5).

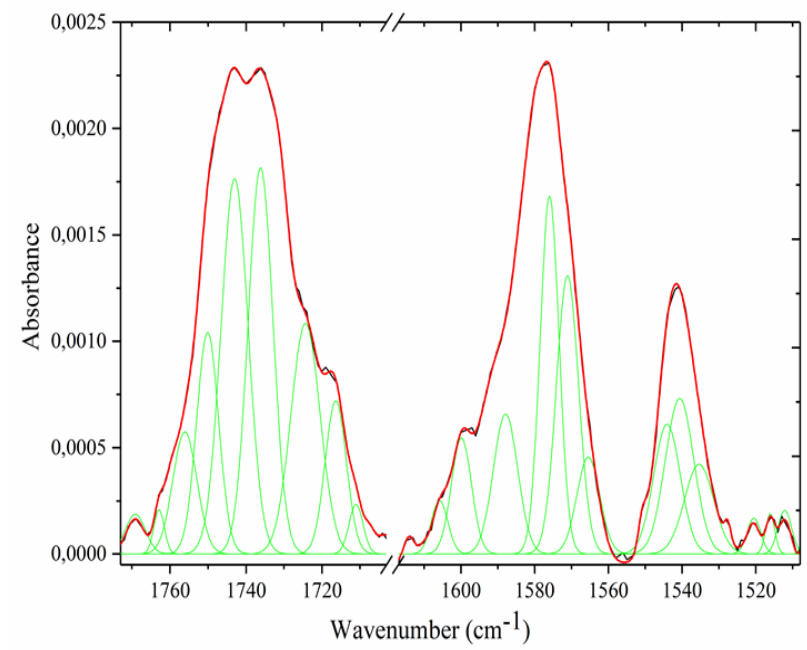

Figure 5. Curve-fitting of u-PVC after processing in the range $\left(1500-1800 \mathrm{~cm}^{-1}\right)$

In the interval (1500-1680 $\left.\mathrm{cm}^{-1}\right)$ a number of different subpeaks appear beneath the envelope of the original spectrum. The $\left(v_{\mathrm{as}} \mathrm{COO}^{-}\right)$in $\mathrm{PbSt}_{2}$ gives rise to IR bands at 1514 and $1540 \mathrm{~cm}^{-1}[21,40]$. The characteristic peak of $\mathrm{CaSt}_{2}$ at 1576 $\mathrm{cm}^{-1}$ was initially observed in the stabilizer system and dryblend spectra (Figure 3 and 7). This band in the u-PVC after curve-fitting appears more developed comparatively to the two other products and was assigned to the ( $v_{\text {as }}$ COO) [22, 41]. A new peak appeared at $1544 \mathrm{~cm}^{-1}$, attributed to the intermediate product, lead chloridostearate, $\left(\mathrm{Pb}\left(\mathrm{C}_{17} \mathrm{H}_{35} \mathrm{COO}\right) \mathrm{Cl}\right)$, generated by $\mathrm{PbSt}_{2}$ that neutralized $\mathrm{HCl}$ released from the $\mathrm{PVC}$ chains Eq. $(4,5)[40]$.

The spectrum region $\left(1700-1800 \mathrm{~cm}^{-1}\right)$ is constituted by many sub-peaks belonging to carbonyl groups coming from either the stabilization reactions or merely the oxidation of the polymer chains [40].

The formation of stearic acids (HSt) coming from the $\mathrm{HCl}-$ scavenging by the $\mathrm{PbSt}_{2}, \mathrm{CaSt}_{2}$ gave rise to two peaks at 1750 and $1708 \mathrm{~cm}^{-1}$ due to the monomeric form of this acid for the first and to the dimeric form for the second (Eq. $(5,7)$ and Eq. $(6,8))[40,42]$.

The absorption band at $1742 \mathrm{~cm}^{-1}$ relatively well developed is that of esters, bonded to the PVC chains. These groups come from the substitution of the labile chlorine atoms of the PVC chains by the stearate groups of the $\mathrm{PbSt}_{2}$ via the Frye-Horst 
mechanism Eq. (9) [40, 42, 43]. A bit later, the resulting ester groups can dissociate from the molecular chains, abstracting adjacent methylenic hydrogen atoms to form $\mathrm{HSt}$ and conjugated vinyl as depicted by Eq. (10) [40, 43-45].

A scavenging reaction, which cannot be highlighted by FTIR, ensured by TBLS, and relaying the two other metal stearate scavengers after they have reacted, has been described by others to occurs as shown in Eq. (11) [45]

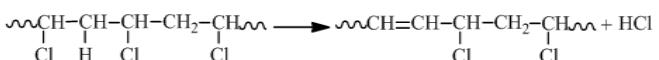

$$
\begin{aligned}
& \mathrm{Pb}\left(\mathrm{C}_{17} \mathrm{H}_{35} \mathrm{COO}\right)_{2}+\mathrm{HCl} \longrightarrow \mathrm{Pb}\left(\mathrm{C}_{17} \mathrm{H}_{35} \mathrm{COO}\right) \mathrm{Cl}+\mathrm{C}_{17} \mathrm{H}_{35} \mathrm{COOH} \\
& \left(1514,1540 \mathrm{~cm}^{-1}\right) \quad\left(1544 \mathrm{~cm}^{-1}\right) \quad\left(1750 \mathrm{~cm}^{-1}\right) \\
& \mathrm{Pb}\left(\mathrm{C}_{17} \mathrm{H}_{35} \mathrm{COO}\right) \mathrm{Cl}+\mathrm{HCl} \longrightarrow \mathrm{PbCl}_{2}+\mathrm{C}_{17} \mathrm{H}_{35} \mathrm{COOH} \\
& \left(1708 \mathrm{~cm}^{-1}\right)
\end{aligned}
$$

$$
\mathrm{Ca}\left(\mathrm{C}_{17} \mathrm{H}_{35} \mathrm{COO}\right)_{2}+\mathrm{HCl} \longrightarrow \mathrm{Ca}\left(\mathrm{C}_{17} \mathrm{H}_{35} \mathrm{COO}\right) \mathrm{Cl}+\mathrm{C}_{17} \mathrm{H}_{35} \mathrm{COOH}
$$$$
\left(1750 \mathrm{~cm}^{-1}\right)
$$

$$
\mathrm{Ca}\left(\mathrm{C}_{17} \mathrm{H}_{35} \mathrm{COO}\right) \mathrm{Cl}+\mathrm{HCl} \rightleftharpoons \mathrm{CaCl}_{2}+\mathrm{C}_{17} \mathrm{H}_{35} \mathrm{COOH}
$$$$
\left(1708 \mathrm{~cm}^{-1}\right)
$$

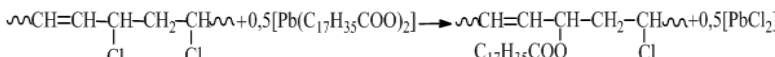

$$
\begin{aligned}
& \left(1514,1540 \mathrm{~cm}^{-1}\right) \quad\left(1742 \mathrm{~cm}^{-1}\right)
\end{aligned}
$$

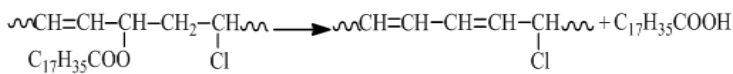

$3 \mathrm{PbO} \cdot \mathrm{PbSO}_{4} \cdot \mathrm{H}_{2} \mathrm{O}+6 \mathrm{HCl} \longrightarrow 3 \mathrm{PbCl}_{2}+\mathrm{PbSO}_{4}+4 \mathrm{H}_{2} \mathrm{O}$

\subsection{Thermal aging effects on the different PVC aspects}

\section{(1) Pristine PVC powder}

In (Figure 6) are reported the FTIR-ATR spectra of the pPVC for different aging stages. It was observed that the intensity of the $(\mathrm{C}-\mathrm{Cl})$ peaks at $\left(610,635\right.$ and $\left.690 \mathrm{~cm}^{-1}\right)$ and those of $\left(\mathrm{CH}, \mathrm{CH}_{2}\right)$ at $\left(955,1197,1253,1329,1425 \mathrm{~cm}^{-1}\right)$ decrease with increasing aging time, very probably because of a dehydrochlorination process.

It is still interesting to notice that the oxidation of the polymeric chains did not occur and that although the aging was performed in an oxygenated environment. However, in the work of Chabira et al. [46] it was observed that aging of thin PVC films in the presence of oxygen led to the growing of hydroperoxides and carbonyls bands at $3500 \mathrm{~cm}^{-1}$ and 1720 $\mathrm{cm}^{-1}$ respectively in reason of the radical chains reaction with surrounding oxygen.

\section{(2) Dry-blend}

In (Figure 7) are reported the FTIR-ATR spectra of the dryblend for different aging stages. A very weak shoulder on the left side of the broad absorption band around $1425 \mathrm{~cm}^{-1}$ appeared. Its maximum revealed by curve-fitting is centered at $1576 \mathrm{~cm}^{-1}$. It belongs to (COO) of $\mathrm{CaSt}_{2}$, its intensity increased during the first sixty days and then slightly decreased till the end.

Surprisingly its increase during the first thirty days coincided with the decrease of the characteristic peaks of
$\mathrm{CaCO}_{3}\left(712,1795 \mathrm{~cm}^{-1}\right)$ and that of the stabilizer $(875,1425$ $\mathrm{cm}^{-1}$ ). This suggests that $\mathrm{CaCO}_{3}$ has very probably reacted with the $\left(\mathrm{COO}^{-}\right)$of fatty acid as described in Eq. (12). However, it remains difficult to know which of $\mathrm{PbSt}_{2}$ or $\mathrm{CaSt}_{2}$ provide the $\left(\mathrm{COO}^{-}\right)$to allow it. This type of reaction has been still already described by Hatsuo Ishida et al., (1985) who used metal stearate to reduce the free energy of the fillers surface $\left(\mathrm{CaCO}_{3}\right)$ reducing agglomeration in the polymer composite [47].

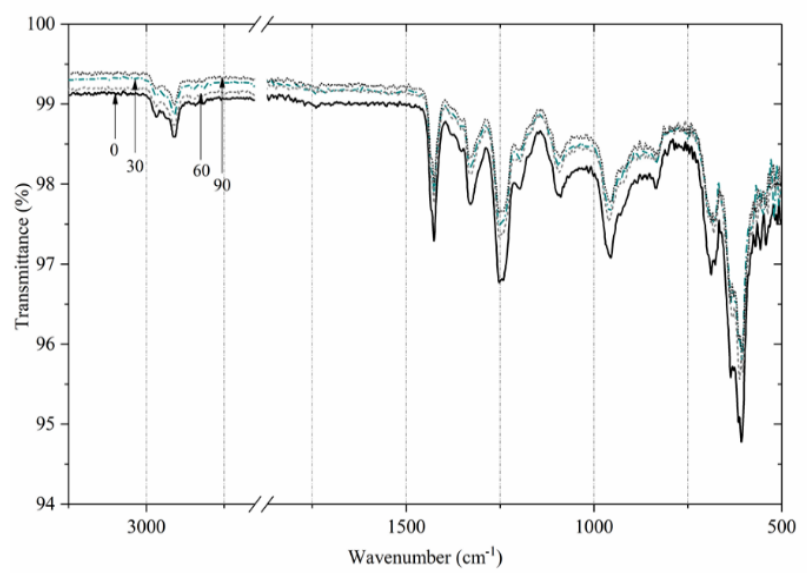

Figure 6. FTIR-ATR spectra of p-PVC for different aging time $(0,30,60$ and 90 days $)$

$$
\begin{gathered}
\mathrm{CaCO}_{3}+2 \mathrm{RCOO}^{-} \rightleftharpoons \\
\left(1576 \mathrm{~cm}^{-1}\right)
\end{gathered}
$$

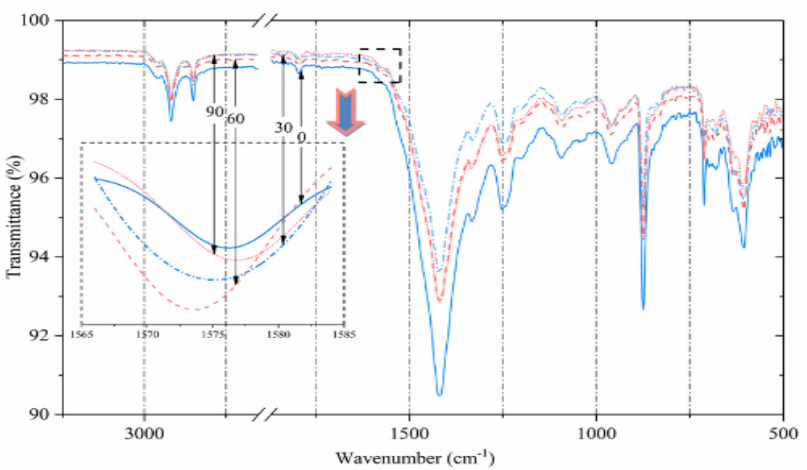

Figure 7. FTIR-ATR spectra of the dry-blend for different aging time $(0,30,60$ and 90 days)

\section{(3) Rigid PVC}

Impact of the thermal aging on the chemical structure. On (Figure 8) are reported the FTIR-ATR spectra of u-PVC for four different aging stages.

Thermal aging also affected the global aspect of the IR spectrum. This occurred in three distinguishable regions. The first was in the range $\left(500-1500 \mathrm{~cm}^{-1}\right)$, showing a decrease of the peaks at $610,690 \mathrm{~cm}^{-1}$ and at 1253, $1329 \mathrm{~cm}^{-1}$ corresponding to the $(\mathrm{v} \mathrm{C}-\mathrm{Cl})$ and $(\delta(\mathrm{C}-\mathrm{H})-\mathrm{Cl})$ respectively [17-19]. Likewise, the peaks belonging to the stabilizer $(805$, $833,875,965,1019,1047,1101$ and $1198 \mathrm{~cm}^{-1}$ ) decrease progressively with aging indicating its consumption by providing stabilization to polymer during aging.

A second region in the interval $\left(2750-3750 \mathrm{~cm}^{-1}\right)$ showed also noticeable changes. Two singular peaks appeared at 2850 
and $2917 \mathrm{~cm}^{-1}$, corresponding to (UC-H) of PVC chains or of the stabilizer, they can also belong to the $(\mathrm{vC}-\mathrm{O})$ in the $\mathrm{CaCO}_{3}$ $[17,20,23,36]$. They increased during the first 60 days of aging and then decrease until the end. It can be noticed that this progression is very similar to that of the $(\mathrm{C}=\mathrm{O})$ bond of the monomeric stearic acid $\left(1750 \mathrm{~cm}^{-1}\right)$ (Figure 9). This allows assuming that HSt (Eq. (5), Eq. (7)) can migrate and accumulate outside the tube surface [48]. Indeed, the ATR analysis being carried out by contact with the tube surface, the carboxylate and methylene groups belonging to the fatty acids display a stronger signal.

The decrease of the wide absorption band around $3400 \mathrm{~cm}^{-1}$ belonging to the $(\mathrm{v} \mathrm{O}-\mathrm{H})$ of hydroperoxide indicates their progressive decomposition, contributing in the formation of carbonyl groups such as esters, ketones, etc., whose peaks appear in the interval $\left(1700-1780 \mathrm{~cm}^{-1}\right)$ [49].

The third region encompasses the carbonyls and the carboxylate groups (1500-1800 $\mathrm{cm}^{-1}$ ). The analysis of (Figure 5 ) let us observe several vibrations corresponding to carbonyl groups, such as the carboxylic acids $\left(1708 \mathrm{~cm}^{-1}\right)$, ketones $\left(1720 \mathrm{~cm}^{-1}\right)$ esters $\left(1742 \mathrm{~cm}^{-1}\right)$, peresters, peracids and rlactones $\left(1770-1780 \mathrm{~cm}^{-1}\right)$ etc.

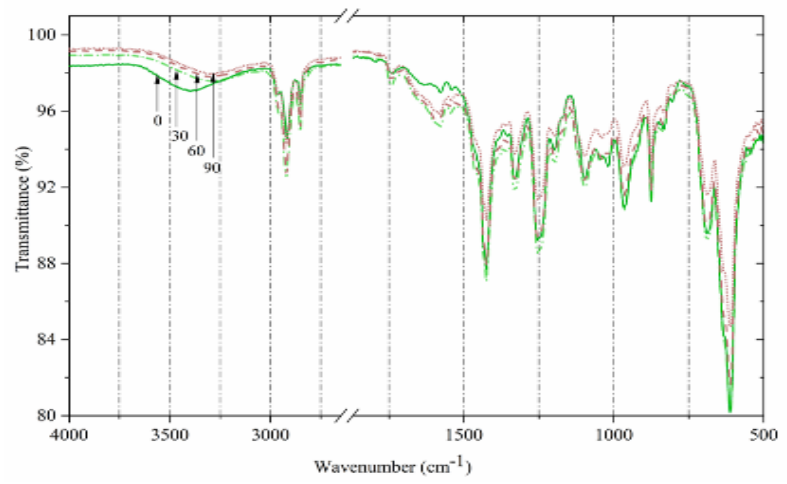

Figure 8. FTIR-ATR spectra of u-PVC for different aging time $(0,30,60$ and 90 days $)$

In fact, the graphical representation of the integrated peakarea of the HSt, esters and carboxylate sub-peaks as a function of the aging time gives a good insight on the relation existing between the carboxylates consumption and the esters formation (Figure 9).

The sub-peaks at 1514,1540 and $1576 \mathrm{~cm}^{-1}$ of $\mathrm{PbSt}_{2}$ and $\mathrm{CaSt}_{2}$ respectively, belonging to their remaining concentration after processing, increase noticeably until 30 days of aging. Such a behavior argues in favor of the migration of the stabilizer from the core of the tube to its surface as described above [48].

The increase of the absorbance at 1750 and $1708 \mathrm{~cm}^{-1}$ reveals the formation of monomeric and dimeric $\mathrm{HSt}$ respectively, corresponding to the first and second step of the scavenging action of $\mathrm{PbSt}_{2}$ and $\mathrm{CaSt}_{2}$, as described in (Eq(5), Eq. (7)) and in (Eq. (6), Eq. (8)) [40, 42]. The lowering of dimeric HSt may be due to its reaction with the formed calcium chloride Eq. (8) [50].

The decrease of the lead chloridostearate $\left(1544 \mathrm{~cm}^{-1}\right)$ which reaches a minimum during the first 30 days coincide with the maximum of the dimeric HSt formation meaning that Eq. (6) is very effective during this period of time.

The absorbance of ester groups $\left(1742 \mathrm{~cm}^{-1}\right)$ do not change over the first 30 days and it is only after this duration that they know a significant increase. This coincides with the decrease of the carboxylate absorption at $\left(1514,1540 \mathrm{~cm}^{-1}\right)$ indicating the formation of esters groups by the reaction of $\mathrm{PbSt}_{2}$ with PVC chain via the Frye-Horst mechanism similarly to what occurred during processing Eq. (9).

After 60 days despite the stabilizer continue to be consumed the esters start an unexpected rapid decrease. This can be due to the fact that ester groups' consumption is relevant to a dissociation mechanism via the abstraction of methylenic hydrogen atoms as described in Eq. (10) leading to the formation of acid molecules and contributes to increase the polyene sequences [45].

On the other hand, the absorbance of carboxylates of $\mathrm{CaSt}_{2}$ at $1576 \mathrm{~cm}^{-1}$ increases until to reach a maximum at 60 days. As for $\mathrm{PbSt}_{2}$ this maximum reveals the migration process of the $\mathrm{CaSt}_{2}$ toward the tube surface, although it lasts a little bit longer (30 days more). This difference in the behavior between these two types of metal stearate can be explained by two reasons:

The concentration of $\mathrm{CaSt}_{2}$ can be raised via the reaction of the $\left(\mathrm{COO}^{-}\right)$of the fatty acid with $\mathrm{CaCO}_{3}$ leading to the formation of $\mathrm{CaSt}_{2} \mathrm{Eq}$. (12) [47] and can contribute to compensates, the consumed amount used to scavenge $\mathrm{HCl} \mathrm{Eq.}$ $(7,8)$ and to increase its concentration.

This can also be explained by the fact that $\mathrm{PbSt}_{2}$ ensures two stabilizing actions which consists in replacing labile chlorine of the PVC chains and $\mathrm{HCl}$-scavenging in the same time. While, $\mathrm{CaSt}_{2}$ which is rather a lubricant, is also known to relay $\mathrm{PbSt}_{2}$ in the HCl-scavenging [39].

Therefore, in the beginning of the thermal aging its rate of migration is higher than scavenging since this last action is rather ensured by $\mathrm{PbSt}_{2}$. This allows its accumulation on the tube surface. After 60 days, period at which $\mathrm{PbSt}_{2}$ is relatively well consumed, the $\mathrm{CaSt}_{2}$ relays the $\mathrm{PbSt}_{2}$ to scavenge $\mathrm{HCl}$ explaining thus its drastic consumption (curve 4, Figure 9).

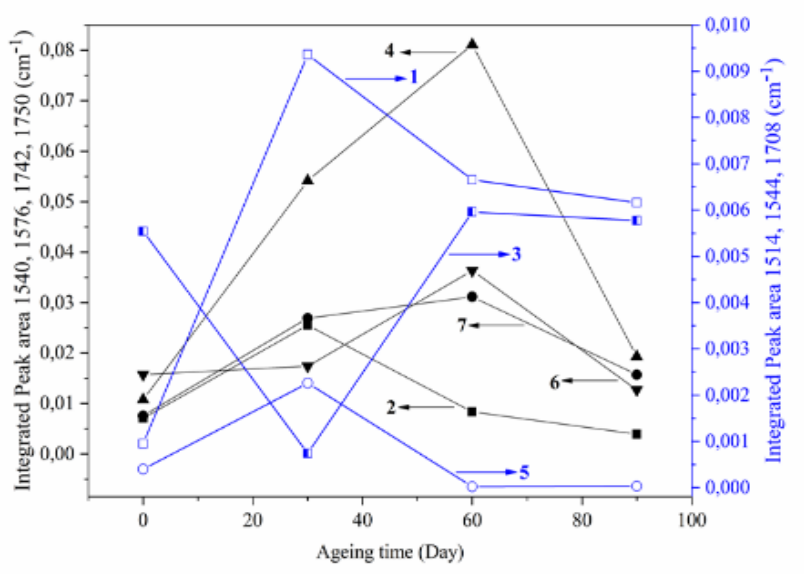

Figure 9. Integrated peak area of the absorption bands of $\mathrm{u}$ PVC at 1) $\square 1514 \mathrm{~cm}^{-1}$, 2) $\left.1540 \mathrm{~cm}^{-1}, 3\right) \mathbf{1 5 4 4 \mathrm { cm } ^ { - 1 } , 4 )}$

$\Delta 1576 \mathrm{~cm}^{-1}$, 5)॰1708 $\mathrm{cm}^{-1}$, 6) $\boldsymbol{\nabla} 1742 \mathrm{~cm}^{-1}$, and 7)•1750 $\mathrm{cm}^{-}$ ${ }^{1}$ versus aging time

Impact of the thermal aging on the mechanical properties. On (Figure 10) are reported the stress-strain curves of u-PVC thermally aged at $60{ }^{\circ} \mathrm{C}$. The unaged material shows a typical viscoelastic behavior [51].

Aging seems to not affect it so significantly. For almost all the curves the first step of the deformation corresponds to the elastic deformation. Beyond the elastic limit the stress goes 
through a maximum corresponding to the yield point followed by a plastic deformation. At the beginning of the plastic deformation in the narrow section of the test-piece appears necking which flows along this section [52-54].

At the last stage where no more flow occurs the material slightly stiffen (strain hardening) to suddenly break in a ductile manner. With aging the mechanical behavior changed. The slope of linear elastic portion of the curve increase significantly revealing a stiffening of the material. The yield stress increased as well with the increasing aging time. The portion of the curves corresponding to the plastic deformation, leveled off and remained as such until failure, excepting for the more aged samples where a shy increase of the stress at the end occurred.

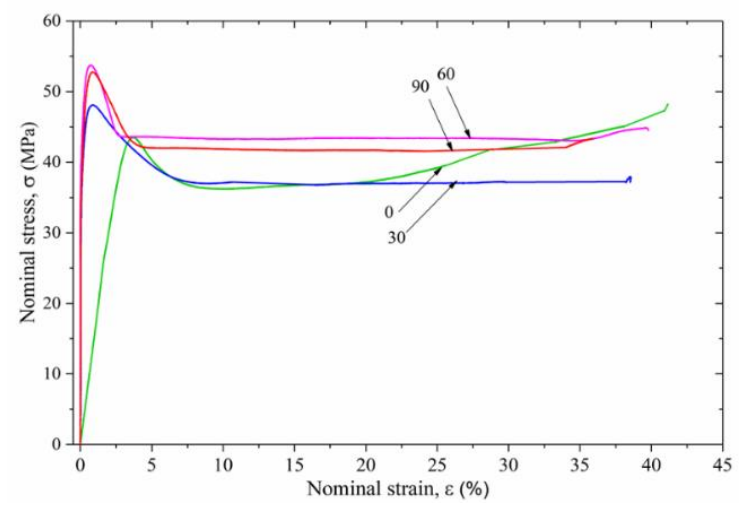

Figure 10. Stress-strain curves of u-PVC after 0, 30, 60 and 90 days of aging

To better show the effects of aging on the mechanical properties, the variation of the $\mathrm{E}, \varepsilon_{\mathrm{b}}, \sigma_{\mathrm{y}}$ and $\sigma_{\mathrm{b}}$ with aging time are reported in (Figure 11.A, 11.B).
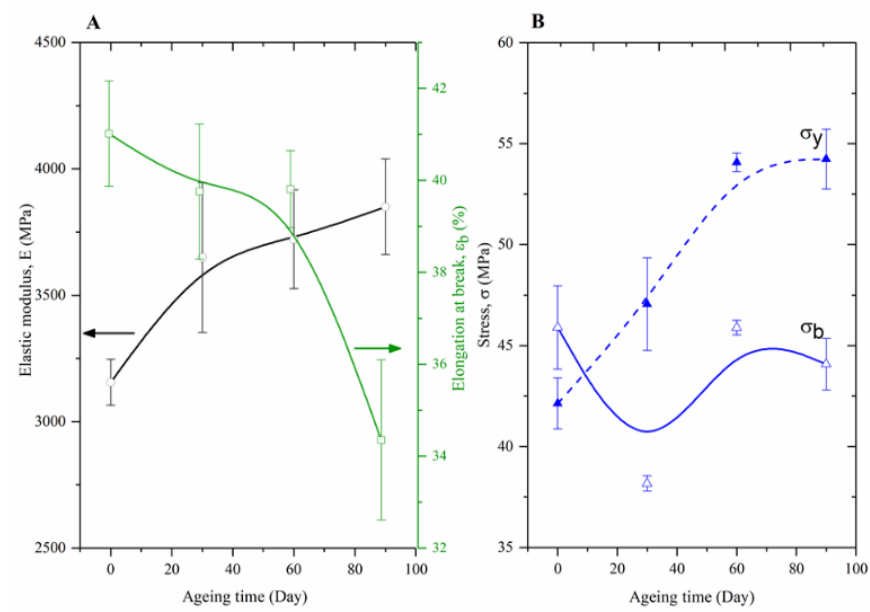

Figure 11. Tensile properties: (A) E, $\varepsilon_{b}$ and (B) $\sigma_{y}, \sigma_{b}$ of $u-$ PVC versus aging time

It can be observed that $\mathrm{E}$ increased with aging time. The increase was more important during the first 30 days of aging with a rate of $15.64 \%$. Then the progression became slower and reached a global increase at the end of the aging of $22 \%$. The $\sigma_{y}$ evolved similarly to $\mathrm{E}$ with the increasing aging time. After 60 days it increased by $28.33 \%$, and then for the last aging stage the progression slowed down. The $\mathrm{E}$ and $\sigma_{\mathrm{y}}$ reveal the increasing elastic character of the material, most probably because of crosslinking reactions which tend to stiffen it [55, 56]. Khemici et al. have shown that when PVC is aged between $39.5{ }^{\circ} \mathrm{C}$ and $80{ }^{\circ} \mathrm{C}$, elastic modulus increases with aging time. They suppose that, this is due to the effect of the molecular mobility diminution and is also related to structural relaxation accompanied by a lowering of the free volume in the material [57].

The $\sigma_{\mathrm{b}}$ evolved irregularly; after 30 days it decreased by at least $16.82 \%$, and then increased again to reach after 60 days a value almost equal to that of the beginning. At the last stage, it started a slight decrease but remained not so far from the precedent value.

The increase of E revealed the stiffening of the material. On another hand the $\varepsilon_{\mathrm{b}}$ decreases progressively during the two first aging stages $(\approx 3 \%)$ to suddenly drop at the last stage to about $16.25 \%$. This mechanical greatness is very sensitive to the microstructural changes caused either by crosslinking or chain scissions reactions since the firsts delay the drop of the $\varepsilon_{\mathrm{b}}$ and increase the elastic character of the material. Chain scissions tend to lower $\varepsilon_{\mathrm{b}}$. which is very sensitive to the damages caused to the material surface and highlights thus the effect of chain scissions which are probably more important at the surface at the end of aging. $\varepsilon_{\mathrm{b}}$ revealed the decrease of the material ductility $[55,56]$.

\section{CONCLUSIONS}

This study is devoted to the thermal aging at $60^{\circ} \mathrm{C}$ performed on PVC under different aspects (i.e. p-PVC, dryblend and u-PVC). This allowed seeing how each of these aspects is affected by the thermal aging. Indeed, the p-PVC does not oxidize and the absorption bands of the $(\mathrm{C}-\mathrm{H})$ and $(\mathrm{C}$ $\mathrm{Cl})$ decrease in intensity in reason of a dehydrochlorination process. For the dry-blend, the absorption bands of the IR spectrum decrease in intensity. However, an increasing absorption band at $1576 \mathrm{~cm}^{-1}$ reveals the reaction of the $\mathrm{CaCO}_{3}$ with the carboxylate groups of fatty acids leading to the formation of $\mathrm{CaSt}_{2}$.

Against all odds, it is the u-PVC which shows the more changing IR spectrum with aging time. It appears a growing carbonyl band due to the combined effect of the surrounding oxygen reacting with the polymeric chains but also by reaction of $\mathrm{PbSt}_{2}$ via the Frye-Horst mechanism, leading to ester groups formation revealed by an absorption band at $\left(1742 \mathrm{~cm}^{-1}\right)$. Chloridostearate $\left(1544 \mathrm{~cm}^{-1}\right)$ and stearic acids under its monomeric and dimeric form (1750 and $\left.1708 \mathrm{~cm}^{-1}\right)$ are also formed from $\mathrm{PbSt}_{2}$ by $\mathrm{HCl}$-scavenging.

It has been seen that $\mathrm{CaSt}_{2}$ provides a lower stabilizing action compared to $\mathrm{PbSt}_{2}$ since $\mathrm{CaSt}_{2}$ is rather used as a lubricant but it can also relay $\mathrm{PbSt}_{2}$ in the $\mathrm{HCl}$-scavenging. The structural changes undergone by the u-PVC affects noticeably the mechanical properties. It has been found that the elastic modulus increases with aging time indicating progressive stiffening due to dehydrochlorination process accompanied by crosslinking reactions. It can also be due to the molecular mobility diminution related to a structural relaxation leading to the material free volume lowering. The irregular variations of the $\sigma_{b}$ disclose the competition between the crosslinking reactions and chain scissions. However, the decrease of the $\varepsilon_{b}$, slow in the beginning and abrupt at the end, seems to reveal that crosslinking reactions are more effective in the beginning, while, chain scissions which weaken the material become predominant at the end. The sudden drop of 
the $\varepsilon_{\mathrm{b}}$ after 60 days coincided with the stabilizers consumption which became effective at this same period of time.

Finally, it can be concluded that the comparison of how PVC behaves under its three different aspects in regard to thermal aging gave a good insight on the stabilizer action before PVC processing but also after. It could be still interesting to notice that in a future work it will be tried to show how these stabilizers can migrate toward transported water and how they can adversely affect the environment.

\section{ACKNOWLEDGMENT}

The authors would like to thank Sir Allahoum Foudhil director of the SARL PLASTUB-Ghardaïa and their members of society for the help and the providing of the different raw material needed to carry out this study.

\section{REFERENCES}

[1] Li B. (2003). Influence of polymer additives on thermal decomposition and smoke emission of poly (vinyl chloride). Polymer Degradation and Stability 82: 467476. https://doi.org/10.1016/S0141-3910(03)00201-5

[2] Krongauz VV, Lee YP, Bourassa A. (2011). Kinetics of thermal degradation of poly (vinyl chloride). Journal of Thermal Analysis and Calorimetry 106: 139-149. https://doi.org/10.1007/s10973-011-1703-6

[3] Sarvetnick HA. (2005). Polyvinyl chloride (PVC). Van Nostrandís Encyclopedia of Chemistry, John Wiley \& Sons, Inc.

[4] Awham MH, Zaid Ghanem MS. (2011). A study of some mechanical behavior on a thermoplastic material. Journal of Al-Nahrain University 14(3): 58-65. https://doi.org/10.22401/JNUS.14.3.08

[5] Yousif E, Ahmed A, Abood R, Jaber N, Noaman R, Yusop R. (2014). Poly (vinyl chloride) derivatives as stabilizers against photodegradation. Journal of Taibah University for Science 1-10. https://doi.org/10.1016/j.jtusci.2014.10.003

[6] Martins JN, Freire E, Hemadipour H. (2009). Applications and Market of PVC for Piping Industry. Polímeros: Ciência e Tecnologia 19(1): 58-62. https://doi.org/10.1590/S0104-14282009000100014

[7] Yarahmadi N, Jakubowicz I, Gevert T. (2001). Effects of repeated extrusion on the properties and durability of rigid PVC scrap. Polymer Degradation and Stability 73: 93-99. https://doi.org/10.1016/S0141-3910(01)00073-8

[8] Tester DA. (2005). The processing of rigid PVC. In: Burgess RH (eds) Manufacture and processing of PVC. Elsevier Applied Science Publishers, England.

[9] Al-Malack MH. (2001). Migration of lead from unplasticized polyvinyl chloride pipes. Journal of Hazardous Materials 82(3): 263-274. https://doi.org/10.1016/S0304-3894(00)00366-6

[10] Stern BR, Lagos G. (2008). Are there health risks from the migration of chemical substances from plastic pipes into drinking water? A review. Human and Ecological Risk Assessment 14: 753-779. https://doi.org/10.1080/10807030802235219

[11] Wang SJ, Zhang H, Shao LM, Liu SM, He PJ. (2014). Thermochemical reaction mechanism of lead oxide with poly(vinylchloride) in waste thermal treatment.
Chemosphere

117:

353-359.

https://doi.org/10.1016/j.chemosphere.2014.07.076

[12] Whelton AJ, Nguyen T. (2013). Contaminant migration from polymeric pipes used in buried potable water distribution systems: A review. Critical Reviews in Environmental Science and Technology 43: 679-751. https://doi.org/10.1080/10643389.2011.627005

[13] Holzner S. (2011). Physics I For Dummies. 2nd ed. Wiley Publishing Inc. Indianapolis, Indiana.

[14] Ajay Polymers. MFR: Rigid uPVC \& cPVC Pipes \& Fittings. http://www.ajaypolymers.in/manufacturingprocess.php/, accessed on 2008.

[15] Chabira SF, Sebaa M, G'sell C. (2011). Oxidation and crosslinking processes during thermal aging of lowdensity polyethylene films. Journal of Applied Polymer Science 124: 5200-5208. https://doi.org/10.1002/app.34080

[16] Yagoubi W, Abdelhafidi A, Sebaa M, Chabira SF. (2015). Identification of carbonyl species of weathered LDPE films by curve fitting and derivative analysis of IR spectra. Polymer Testing 44: 37-48. https://doi.org/10.1016/j.polymertesting.2015.03.008

[17] Krimm S, Liang CY. (1956). Infrared spectra of high polymers.IV. Polyvinyl chloride, polyvinylidene chloride, and copolymers. Journal of Polymer Science 22: 95-112. https://doi.org/10.1002/pol.1956.1202210012

[18] Savrik SA, Balkose D, Ulutan S, Ulku S. (2010). Characterization of poly (vinyl chloride) powder produced by emulsion polymerization. Journal of Thermal Analysis and Calorimetry 101: 801-806. https://doi.org/10.1007/s10973-010-0942-2

[19] Beltran M, Marcilla A. (1997). Fourier transform infrared spectroscopy applied to the study of PVC decomposition. European. Polymer Journal 33(7): 11351142. https://doi.org/10.1016/S0014-3057(97)00001-3

[20] Robinet L, Corbeil MC. (2003). The characterization of metal soaps. Studies in Conservation 48: 23-40.

[21] Silva BD, Gelbrich T, Hursthouse MB, Higgitt CL, Saunders DR. (2003). The characterisation of lead fatty acid soaps in protrusions in aged traditional oil paint. Polyhedron 22: https://doi.org/10.1016/S0277-5387(03)00461-3

[22] Benavides R, Edge M, Allen NS. (1994). The mode of action of metal stearate stabilisers in poly (vinyl chloride). I. Influence of pre-heating on melt complexation. Polymer Degradation and Stability 44(3): 375-378. https://doi.org/10.1016/0141-3910(94)90096-5

[23] Paterakis AB. (2003). The influence of conservation treatments and environmental storage factors on corrosion of copper alloys in the ancient Athenian agora. Journal of the American Institute for Conservation 42(2): 313-339. https://doi.org/10.2307/3180074

[24] Knuutinen U, Norrman A. (2000). Wax analysis in conservation objects by solubility studies. FTIR and DSC. 15th World Conference on Nondestructive Testing, Roma, Italy 15-21.

[25] Masae M, Pitsuwan P, Sikong L, Kooptarnond K, Kongsong P, Phoempoon P. (2014). Thermo-physical characterization of paraffin and beeswax on cotton fabric. Thammasat International Journal of Science and Technology 19(4): 69-77.

[26] Derrick MR, Stulik D, Landry JM. (1999). Infrared spectroscopy in conservation science. Library of Congress Cataloging-in-Publication Data, USA. 
[27] Shearer GL. (1989). An evaluation of Fourier transform infrared spectroscopy for the characterization of organic compounds in art and archaeology. Ph.D. Dissertation. Department of Conservation and Materials Science. University College, London, GBR.

[28] Trettenhahn GLJ, Nauer G, Neckel A. (1993). Vibrational spectroscopy on the $\mathrm{PbO}-\mathrm{PbSO}_{4}$ system and some related compounds. Vibrational Spectroscopy 5:85-100.

https://doi.org/10.1016/j.polymertesting.2015.03.008

[29] Grasselli MC, Baran EJ. (1984). IR spectroscopic characterization of tetrabasic lead sulphate. Journal of Materials Science Letters 3(11): 949-950. https://doi.org/10.1007/BF00720325

[30] Silverstein RM, Webster FX, Kiemle DJ. (2005). Spectrometric identification of organic compounds. 7th ed. John Wiley \&Sons Inc, USA.

[31] Evanson KW, Thorstenson TA, Urban MW. (1991). Surface and interfacial FTIR spectroscopic studies of latexes. II. Surfactant-copolymer compatibility and mobility of surfactants. Journal of Applied Polymer Science 42: 2297-2307. https://doi.org/10.1002/app.1991.070420821

[32] Matsuhiro B, Osorio-Román IO, Carbohydr TR. (2012). Vibrational spectroscopy characterization and anticoagulant activity of a sulfated polysaccharide from sea cucumber Athyonidium chilensis. Carbohydrate Polymers 88: 959-965. https://doi.org/10.1016/j.carbpol.2012.01.052

[33] Vallat-Joliveau F, Delahaye-Vidal A, Figlarz MJ. (1995). Some Structural and textural aspects of tribasic lead sulfate precipitation during the mixing of lead-acid battery positive paste. Journal of the Electrochemical Society 142(8): 2710-2716. https://doi.org/10.1149/1.2050079

[34] Anddersen FA, Brecevic L. (1991). Infrared spectra of amorphous and crystalline calcium carbonate. Acta Chemica Scandinavica 45: 1018-1024. https://doi.org/10.3891/acta.chem.scand.45-1018

[35] Miller FA, Wilkins CH. (1952). Infrared spectra and characteristic frequencies of inorganic ions. Analytical chemistry 24(8): 1253-1294. https://doi.org/10.1021/ac60068a007

[36] Pathak RP, Sharma P, Murari R. (2012). Characterization of leachate material from dam concrete by X-Ray diffractometer and FTIR. International Journal of Research in Chemistry and Environment 2(4): 58-63.

[37] Gupta U, Singh VK, Kumar V, Khajuria Y. (2015). Experimental and theoretical spectroscopic studies of calcium carbonate $\left(\mathrm{CaCO}_{3}\right)$. Materials Focus 4(2): 164169. https://doi.org/10.1166/mat.2015.1233

[38] Ennaciri Y, Bettach M, Cherrat A, Zegzouti A. (2016). Conversion of phosphogypsum to sodium sulfate and calcium carbonate in aqueous solution. Journal of Materials Environment and Science 7(6): 1925-1933.

[39] Ivan B, Turczanyi B, Kelen T, Angew TF. (1991). Thermooxidative degradation of PVC in solution in the presence of metal stearate stabilizers. Die Angewandte Makromolekulare $\quad$ Chemie $\quad 189$ : 35-49. https://doi.org/10.1002/apmc.1991.051890104

[40] Kalouskova R, Novotna M, Vymazal Z. (2004). Investigation of thermal stabilization of poly(vinyl chloride) by lead stearate and its combination with synthetic hydrotalcite. Polymer Degradation and
Stability

85:

903-909.

https://doi.org/10.1016/j.polymdegradstab.2004.04.008

[41] Gönen M, Öztürk S, Balköse D, Okur S, Ülku S. (2010). Preparation and characterization of calcium stearate powders and films prepared by precipitation and Langmuir- Blodgett techniques. Industrial and Engineering Chemistry Research 49(4): 1732-1736. https://doi.org/10.1021/ie901437d

[42] Volka K, Skorvaga J, Vymazal Z. (1988). The use of i.r. spectroscopy for gaining insight into the mechanism of stabilization of PVC by cadmium stearate. Spectrochimica Acta Part A: Molecular Spectroscopy 44(12): 1341-1350. https://doi.org/10.1016/05848539(88)80180-6

[43] Frye AH, Horst RW. (1960). The mechanism of polyvinyl chloride stabilization by barium, cadmium, and zinc carboxylates. II. Radioactive tracer studies. Journal of Polymer Science 45(145): 1-12. https://doi.org/10.1002/pol.1960.1204514501

[44] Šimon P, Oremusová J, Valko L. (1991). Influence of metal stearates on thermal stability of polyvinyl chloride) IV. Lead stearate. Chemical Papers 45(3): 389-399.

[45] Michell EWJ. (1986). True stabilization: A mechanism for the behavior of lead compounds and other primary stabilizers against PVC thermal dehydrochlorination. Journal of Vinyl Technology 8(2): 55-65. https://doi.org/10.1002/vnl.730080207

[46] Chabira SF, Sebaa M. (2012). Effect of thermal stabilizers $(\mathrm{Ba} / \mathrm{Cd} / \mathrm{Zn}$ metal salts carboxylate and dibasic lead stearate) on the photodegradation of PVC films. Revue de Science et Technologie 24: 44-61.

[47] Ishida H, Kumar G. (1985). Characterization of composite interfaces. Springer Science+Business Media LLC, New York.

[48] Bodecchi LM, Durante C, Malagoli M, Manfredini M, Marchetti A, Sighinolfi S. (2011). Distribution of heat stabilizers in plasticized PVC-Based: Temperature and time effects. International Journal of Spectroscopy. https://doi.org/doi:10.1155/2011/641257

[49] Gardette JL, Lemaire J. (1991) Photothermal and thermal oxidations of rigid, plasticized and pigmented poly (vinyl chloride). Polymer Degradation and Stability 34(1-3): 135-167. https://doi.org/10.1016/10.1016/01413910(91)90117-A

[50] Oremusová J, Šimon P, Valko L, Kovařík P. (1989). Influence of metal stearates on thermal stability of polyvinyl chloride) I. Calcium stearate. Chemical Papers 43(6): 721-731.

[51] Titow WV. (1984). PVC technology. 4th ed. Elsevier Applied Science Publishers LTD. England.

[52] Dreistadt C. (2007). Analyse expérimentale et modélisation micromécanique du comportement $\mathrm{du}$ polycarbonate soumis aux chargements complexes. Ph.D. Dissertation. Option: Mécanique des matériaux. Université Paul Verlaine de Metz. France.

[53] Lichtle AS. (2007). Etude de la résistance aux chocs de tubes PVC à parois structures: Influence du procédé de fabrication sur les proprieties finales. Ph.D. Dissertation.

[54] Oudet C. (1993). Polymère structure et propriétés. Masson, Paris

[55] Merah N. (2007). Natural weathering effects on some properties of CPVC pipe material. Journal of Materials Processing Technology 191: 198-201. https://doi.org/10.1007/s10973-010-0942-2 
[56] Merah N. Bazoun A, Fazal A, Khan Z. (2013). Weathering degradation mechanisms of chlorinated PVC. International Journal Plastics \& Technology 17(2): 111122. https://doi.org/10.1007/s12588-013-9052-x

[57] Khemici MW, Gourari A, Bendaoud M. (2006). Study of the effect of annealing and physical aging on PVC by the thermally stimulated currents methods. International Journal of Polymer Analysis and Characterization 11(1): 101-114. https://doi.org/10.1080/1023 6660500486440

\section{NOMENCLATURE}

$\begin{array}{ll}\text { PVC } & \text { poly (vinyl chloride) } \\ \text { u-PVC } & \text { unplasticized poly (vinyl chloride) } \\ \text { p-PVC } & \text { pristine poly (vinyl chloride) } \\ \text { OD } & \text { optical density } \\ \text { R }^{2} & \text { coefficient of determination } \\ \text { RH } & \text { relative humidity } \\ \text { ISO } & \text { international organization for standardization } \\ \text { DIN } & \text { deutsches institut für normung } \\ \text { BS EN } & \text { british standard european norm } \\ \text { FTIR } & \text { Fourier transforms infrared } \\ \text { UATR } & \text { universal attenuated total reflectance accessory } \\ \text { I }_{0} & \text { reference infrared intensity }\end{array}$

$\mathrm{W}_{0} \quad$ width of the narrow section, $\mathrm{mm}$

$\mathrm{T}_{0} \quad$ thickness sample, $\mathrm{mm}$

$\mathrm{L}_{0} \quad$ initial distance between grips, $\mathrm{mm}$

$\mathrm{L} \quad$ current distance between grips, $\mathrm{mm}$

TBLS tribasic lead sulfate

$\mathrm{PbSt}_{2} \quad$ lead stearate

$\mathrm{CaSt}_{2}$ calcium stearate

HSt stearic acid

\section{Greek symbols}

$\begin{array}{ll}\sigma_{\mathrm{y}} & \text { yield stress, MPa } \\ \sigma_{\mathrm{b}} & \text { stress at break, MPa } \\ \varepsilon_{\mathrm{b}} & \text { elongation at break, } \% \\ v & \text { stretching vibration } \\ v_{\mathrm{s}} & \text { symmetric stretching vibration } \\ v_{\mathrm{as}} & \text { antisymmetric stretching vibration } \\ \delta & \text { bending vibration } \\ \delta_{\text {in-plane }} & \text { in-plane bending vibration } \\ \delta_{\text {out-of- }} & \text { out-of-plane bending vibration }\end{array}$

